\title{
A economia colonial do Grão-Pará: uma avaliação crítica (1720-1822) ${ }^{1}$
}

\author{
Francisco de Assis Costa ${ }^{2}$
}

\begin{abstract}
Resumo
Com base em exaustivo trabalho de reconstituição de séries que se estendem de 1720 a 1822, o artigo objetiva contribuir para a construção de perspectivas da economia colonial amazônica que enfatizem o contexto global - a capacidade demonstrada de se afirmar como subsistema do Império Colonial Português no contexto do mercado mundial. Ao discutir essa capacidade, avalia a evolução das condições fundamentais de escala e eficiência, entendendo-as como determinadas pelas condições locais de operação do projeto colonial. Tais condições, caracterizadas pelos fundamentos naturais únicos do bioma amazônico, são avaliadas na referência das mudanças institucionais que marcam, vigorosamente, no tempo, a trajetória da economia e sociedade regionais.
\end{abstract}

Palavras-chave: Amazônia; História colonial, Grão-Pará, Economia extrativa, Século XVIII.

\section{Abstract}

The colonial economy of Grão-Pará: a critical evaluation (1720-1822)

Based on work of restoration of time series of some important economic variables that extend from 1720 to 1822 , the paper aims to contribute to a vision of the Amazonian colonial economy that emphasizes the global context - it means a demonstrated ability to assert itself as sub-system of the Portuguese Colonial Empire in the context of world market. In discussing this capacity, the article evaluates the evolution of fundamental conditions of efficiency of the colony, considering them as determined by the peculiar features that assumed the local operation of the colonial project in GrãoPará. These conditions, strongly characterized by the uniqueness of the natural foundations of the Amazonian biome, are evaluated in reference to the institutional changes that mark in time the trajectory of the regional economy and society.

Keywords: Amazonia; Colonial history; Pombal's administration; Grão-Pará JEL N56, N96.

\section{Introdução}

A historiografia brasileira clássica supõe uma oposição entre um projeto colonial agrícola e a ocorrência de situações concretas de economias extrativistas, de acordo com a disponibilidade de capital a ser aplicado no principal meio de produção, o escravo negro. Na Amazônia, um longo período de escassez de

(1) Trabalho recebido em 15 de janeiro de 2010 e aprovado em 14 de outubro de 2010.

(2) Professor Associado da Universidade Federal do Pará, no Programa de Pós-Graduação em Desenvolvimento Sustentável do Trópico Úmido do Núcleo de Altos Estudos Amazônicos (NAEA) e do Programa de Pós-Graduação em Economia do Depto. de Economia, Belém, PA, Brasil. E-mail: francisco_de_assis_costa@yahoo.com.br. 
recursos teria conformado o ciclo da economia extrativista na região ${ }^{3}$, dominado pelas "drogas do sertão", até o reinado de D. José I, substituído por um ciclo agrícola favorecido pela relativa abundância de capitais do período pombalino. A gestão pombalina seria $a$ inflexão, o turning point que marcaria a passagem da situação insustentável representada pelo extrativismo para uma dinâmica estruturada pela agricultura que, alimentada adiante por conjunturas do mercado mundial, sobretudo aquelas ligadas à Guerra da Independência Americana, só encontraria limitação importante na emergência do novo ciclo extrativista centrado na borracha (Dias, 1970; Reis, 1944; Tocantins, 1960).

Não obstante eventual alternativa, a via de realização do projeto colonial dominado pela economia extrativista é vista, nessa perspectiva, como solução inferior, à qual corresponderiam situações marcadas pela escravização indígena e pela pobreza estrutural. Para Sodré, "as regiões vicentina e maranhense" se igualavam nessas condições “... peculiares a todas as zonas coloniais onde não ocorreu o investimento do capital comercial europeu, zonas pobres, de crescimento vegetativo" (Sodré, 1987, p. 129). Diferente do Maranhão, onde os fundamentos alternaram-se ao sabor do grau de riqueza propiciado pelos produtos agrícolas exportados, na Amazônia, a coleta florestal ganhou peso definitivo, posto que as aptidões da região para a agricultura se mostraram limitadas (Idem, p. 115-116).

Prado Jr. aduz o julgamento de que, a partir de então, “...não deu mais que uns miseráveis produtos de expressão comercial mínima e em quantidades restritas", resultado de "formas de atividades" com tal grau de "instabilidade e incerteza" que "... fazem da colonização amazonense muito mais uma aventura que a constituição de uma sociedade estável e organizada" (Prado Jr., 1987, p. 7475). Observada em contraste com as visões precedentes, mediante as quais prevaleceria uma noção de pobreza relativa a variar com os ciclos - se com mais trabalho escravo africano, mais produção agrícola de alta rentabilidade, mais pujança; se com mais trabalho indígena, mais produção extrativa ou produção agrícola de baixa rentabilidade -, a ênfase estrutural da perspectiva do autor aponta para um estado absoluto de carência e miséria cujos ensaios de superação, como os do período pombalino, não constituíram mais que surtos sem consequências maiores. De modo que, sentencia Prado Jr: “... não foi possível ampliar as bases desta produção e dar-lhes pela agricultura mais estabilidade." (Prado Jr., 1987, p. 75).

(3) Quando nos referimos aqui à Amazônia, temos em mente as informações e análises relativas ao componente do Pará na Colônia do Grão-Pará e do Maranhão. 


\section{A polaridade "riqueza" $x$ "pobreza", a divisão social do trabalho colonial e distribuição de seus frutos}

A análise do período colonial no Brasil está recheada da oposição "riqueza" versus "pobreza". Milena Maranho estudou, recentemente, o caso emblemático da recorrente distinção entre a "pobreza de São Paulo" e a "riqueza de Pernambuco" e concluiu pela necessidade de qualificar as ideias envolvidas, matizando-as segundo a importância e o papel característicos das atividades econômicas das localidades na América. A comparação direta de grandezas absolutas não basta (Maranho, 2006, p. 13).

Em relação à Amazônia, noções de pobreza e riqueza têm sido construídas confrontando realidade com expectativas ou comparando escalas. Quando se refere à "miséria dos resultados" da colônia amazônica, como comentado, Prado Jr., por exemplo, alude ao “... frisante contraste entre o que apresentam e o que deles esperava a imaginação escaldante do branco europeu em contato com os trópicos" (Prado Jr., 1987, p. 75). Para Cardoso (1984), "Sub-povoamento e pobreza formavam um círculo vicioso... [tornando a]... Posição do Pará nas exportações da América Portuguesa (...) ainda em 1796, bastante modesta" (Cardoso, 1984, p. 116 e 133). Infere-se que pobreza, nesse caso, constitui o valor absoluto das exportações da colônia pobre, o Pará (R\$ 257:241\$327), comparativamente às colônias ricas, Salvador, Recife e Maranhão (respectivamente, $\mathrm{R} \$ 2.582: 839 \$ 510, \mathrm{R} \$ 1.255: 598 \$ 365$ e $\mathrm{R} \$ 956: 513 \$ 800$ ) e ao total de todas as colônias ( $\mathrm{R} \$ 5.806: 403 \$ 382$ ). No primeiro caso, a "pobreza" qualifica uma situação marcada por esperança contrafeita, posto que referida à escala subjetiva contrariada pela modéstia da dimensão real alcançada pela operação do objeto qualificado; no segundo, ela é expressão da modéstia da escala objetiva do objeto qualificado frente às escalas alcançadas por aparatos pressupostos semelhantes cujas dimensões seriam objetivamente alcançáveis.

Ocorre que tais relações não são suficientes para estabelecer os sentidos propriamente econômicos das grandezas a que se referem. Se dão alguma indicação sobre a eficiência da parte (a Colônia) no anseio primordial do empreendimento mercantil colonial como um todo de maximizar receita, tais relações não fornecem base para julgar a eficácia dos processos subjacentes a tal anseio, seja na ótica reprodutiva do sistema, seja na perspectiva das estratégias operadas em cada uma das suas partes. Para tanto, ter-se-ia que explicitar as estruturas subjacentes e seus movimentos, o que, por seu turno, requer enunciados sobre as relações que estabelecem com os sistemas maiores em que se integram, também em movimento, sobre as condições de aplicação dos seus fundamentos de última instância, materiais e humanos, e sobre a dinâmica dessa aplicação no contexto da divisão social do trabalho que, num plano global, articula sistema 
colonial e mercado mundial assim como, num plano local, articula "produção de subsistência" com "produção de exportação" na reprodução das colônias.

O presente trabalho objetiva contribuir para a construção de perspectivas da economia colonial amazônica que, de um lado, a ponham em um contexto global e que, de outro, valorize as relações entre as condições internas e externas bem como o peso da dependência do passado na observação de sua trajetória e de seu movimento.

Em contexto global, a eficiência da economia da colônia se expressará objetivamente na capacidade demonstrada de se afirmar na economia-mundo como subsistema do Império Colonial Português. Na seção 1, discutiremos essa capacidade na observação da evolução de variáveis fundamentais de escala e eficiência, comparando-as à evolução de sistemas envolventes (economia portuguesa e economia-mundo) e concorrentes (a Colônia do Brasil). Em acréscimo, na mesma seção, apontaremos para possibilidades heurísticas da perspectiva que observa questões de escala e de eficiência, considerando-as, não obstante ligadas ao movimento global, como determinadas pelas condições locais de operação do projeto colonial.

Em dinâmica dependente de trajetória, as mudanças e transformações fundamentais na economia da colônia se expressarão numa marcação do tempo informada pela institucionalidade prevalecente. Assim, na seção 2, detalharemos o Período Colonial em quatro subperíodos relevantes: de 1720 a 1755, regulado pelo Regimento das Missões, de 1756 a 1777, marcado pela administração pombalina, o período posterior, de 1778 até o ano de 1798, quando se extinguem os Diretórios, até 1822, quando será declarada a Independência do Brasil e cessam as estatísticas coloniais. A historiografia discutida coloca, para o primeiro subperíodo, a expectativa de uma economia extrativista incerta e miserável. Para a fase seguinte, a expectativa alimentada é a de que, enfim, após um século e meio desde a inauguração da Colônia, funda-se uma economia estável com eficiência de comércio e a dominância da agricultura, que se consolidará nas fases seguintes, não obstante irregularidades aguçadas pela corrupção dos Diretórios, no primeiro, e dificuldades do mercado mundial, no segundo subperíodo.

\section{0 ciclo longo da economia colonial amazônica}

O empreendimento colonial do Grão-Pará, observado na sua dimensão macro, é a totalidade dos rendimentos obtidos desde a exploração do aparato produtivo que lhe corresponde até sua realização no mercado mundial. Nesse nível, a Colônia expressa seu sentido como particularidade de um todo maior: de um conjunto de empreendimentos coloniais contidos num império e este numa economia-mundo. 
Se designarmos a produção física do Grão-Pará colonial como XT, seu fundamento de recursos humanos (trabalho e gestão) por P, a sua dimensão macro teria uma expressão em $Y \$$, de forma que:

$$
\begin{aligned}
& Y \$=(Y \$ / X \$) \cdot(X \$ / P) \cdot P \\
& (Y \$ / P)=(Y \$ / X \$) \cdot(X \$ / P) \\
& (X \$ / P)=(X \$ / X T) \cdot(X T / P)
\end{aligned}
$$

Onde Y\$ é o Valor Bruto da Produção da Colônia no Mercado Mundial (VBPM $=$ XT a preços vigentes do mercado mundial) e X\$, o Valor da Produção Exportada na Colônia (VBPC $=\mathrm{XT}$ a preços de exportação de Belém para a metrópole). A equação (1) diz que a expansão dessa economia como parte de uma economia-mundo depende da extensão do fator humano passível de incorporação pelo projeto colonial $\mathrm{P}$, das condições internas que determinam a rentabilidade na aplicação desses recursos humanos na colônia $(x=\mathrm{X} \$ / \mathrm{P})$ e das condições externas à colônia, que determinam a capacidade de formação de valor adicionado a partir da metrópole $(m=\mathrm{Y} \$ \mathrm{X} \$=\mathrm{XT} . \mathrm{y} \$ \mathrm{XT} . \mathrm{x} \$=\mathrm{y} \$ \mathrm{x} \$$, para $\mathrm{y} \$$ e $\mathrm{x} \$$ sendo, respectivamente, os preços no mercado mundial e os preços na Colônia). Poder-seia, em primeiro plano, afirmar que a eficiência será correlata ao resultado da aplicação de cada unidade de recurso humano na colônia $(y=Y \$ / P)$, como se lê na equação (2). Por fim, a equação (3) estabelece que as condições internas resultam da produtividade física $(\mathrm{xt}=\mathrm{XT} / \mathrm{P})$ e do preço da produção exportada da Colônia $(\mathrm{x} \$=\mathrm{X} \$ / \mathrm{XT})$. Uma leitura dinâmica seria a de que a expansão do sistema $(\Delta \mathrm{Y} \$=$ $\Delta \mathrm{m}+\Delta \mathrm{x}+\Delta \mathrm{P})$ se fará tanto mais eficiente quanto maior o crescimento da sua produtividade monetária $(\Delta \mathrm{y}=\Delta \mathrm{m}+\Delta \mathrm{x})$, que, por sua vez, depende das variações observadas nas condições externas $(\Delta \mathrm{m}=\Delta \mathrm{y} \$-\Delta \mathrm{x} \$)$ e internas $(\Delta \mathrm{x}=\Delta \mathrm{xt}+\Delta \mathrm{x} \$)$ de operação de seus fundamentos - transacionais e produtivos.

As taxas $\Delta$ foram encontradas por regressão linear da transformação logarítmica de cada variável tomada individualmente em relação ao tempo. ${ }^{4}$ Foram encontradas as taxas pelas regressões independentes de cada série, que, entretanto, cumprem, necessariamente, as condições das equações a diferenças apresentadas. As relações entre as taxas, quando orientadas pelas equações, cumprem as regras das respectivas derivações parciais.

\section{A expansão e seus fundamentos}

De 1720 a 1822, o segundo século após a inauguração da Colônia, em 1616, a economia do Grão-Pará do Império Colonial Português, medida pelo

(4) Para $Y \$$, por exemplo, dado que $Y \$ t+1=Y \$ t .(1+\Delta Y \$) t$ e, portanto, $\ln (Y \$ t+1)=\ln (Y \$ t)+$ $\ln (1+\Delta \mathrm{Y} \$)$, a taxa $\Delta Y \$$ é igual a 1 menos o antilogaritmo do coeficiente linear da regressão de $\ln (\mathrm{Y} \$ \mathrm{t}+1)$, como variável dependente em relação a t, a série de anos em questão, como variável independente. 
VBPM cresceu a uma taxa média de 3,2\% a.a. Assim, atingiu, na fase final do Período Colonial, dimensão 40 vezes maior que o modesto porte no qual se havia mantido por cem anos. A performance de $\mathrm{Y} \$$ se explica pelo crescimento da população sob controle do sistema colonial à taxa de 1,7\% a.a. e pelo incremento da eficiência na aplicação dessa população, $y$, a 1,5\% a.a. (ver Gráfico 1 e Tabela 2 do Anexo).

Gráfico 1

Evolução do Valor Bruto da Produção no Mercado Mundial (VBPM=Y\$), em \$000; Y\$ per capita (y), população da colônia $(\mathrm{P})$, em números índices para 1720 a $1725=100$, Médias móveis quinquenais

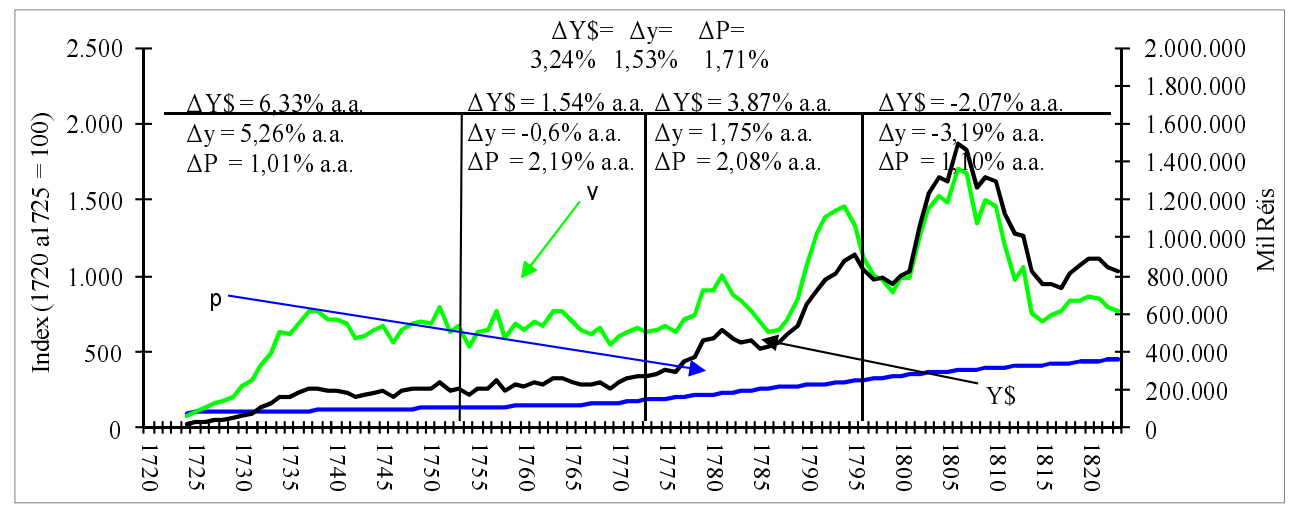

Fonte: Tabelas 1 e 2 do Anexo.

Gráfico 2

Evolução do Valor da Produção Exportada na Colônia (VBPC=X\$) per capita (x) na Amazônia e no Brasil em \$000 e multiplicador de VBPC na metrópole (m), de 1720 a 1822

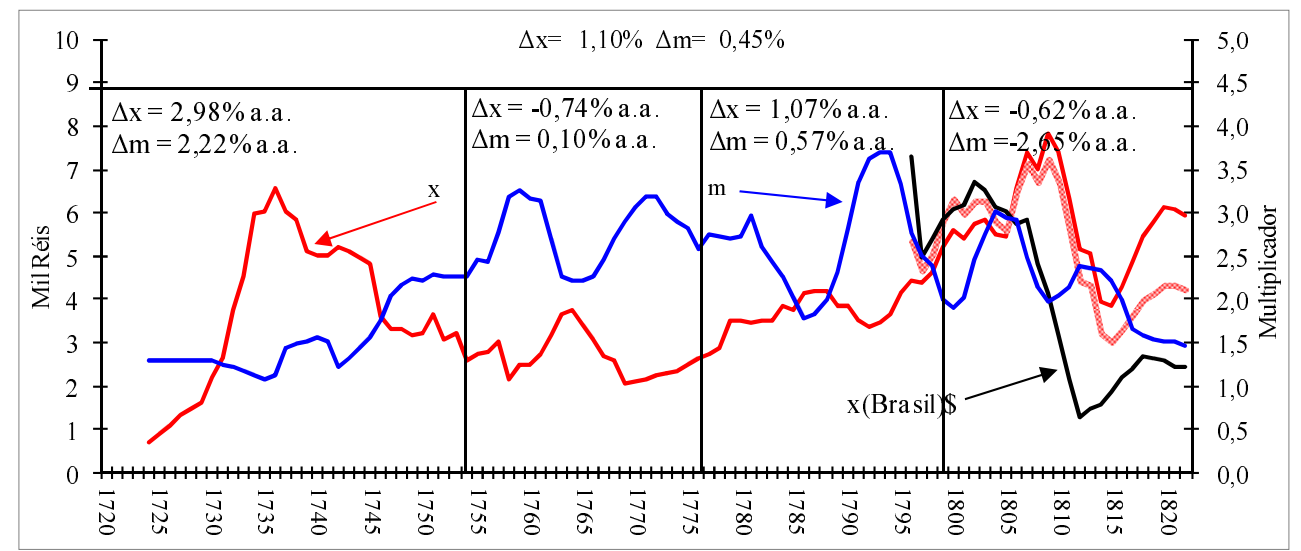

Fonte: Tabela 1 do Anexo. Exportações do Brasil do período 1796 a 1918, a partir das séries produzidas por Roberto Simonsen (1978, p. 431). 4 - Séries demográficas publicadas pelo IBGE, na tabela 1.3. 
Por seu turno, a performance de $y$ explica-se mais pela variação positiva nas condições internas da Colônia expressas em $x$, o valor das exportações per capita, proxy da produtividade monetária, que cresce a 1,1\% a.a., que pelo crescimento a $0,5 \%$ a.a. do fator de formação de valor adicionado no mercado mundial $(m)$ (ver Gráfico 2).

Na base da evolução positiva das condições internas representadas por $x$ estão, principalmente, o crescimento da produtividade física da população sob controle do empreendimento colonial, $x t$, a $0,76 \%$ a.a. e, secundariamente, os preços internos, $x \$$, que evoluíram a $0,33 \%$ a.a. Usando recursos de derivação parcial, enunciar-se-ia, em síntese, que $73 \%$ do desempenho global do empreendimento foi explicado pelo desempenho dos fatores internos da Colônia, o que, por sua vez, se explica, em $68 \%$, pela evolução da sua produtividade física.

Gráfico 3

Evolução da produtividade física (xt em kg per capita) e dos preços de exportação da Colônia ( $\mathrm{x} \$$ em $\$ 000)$ de 1720 a 1820 (Médias móveis quinquenais)

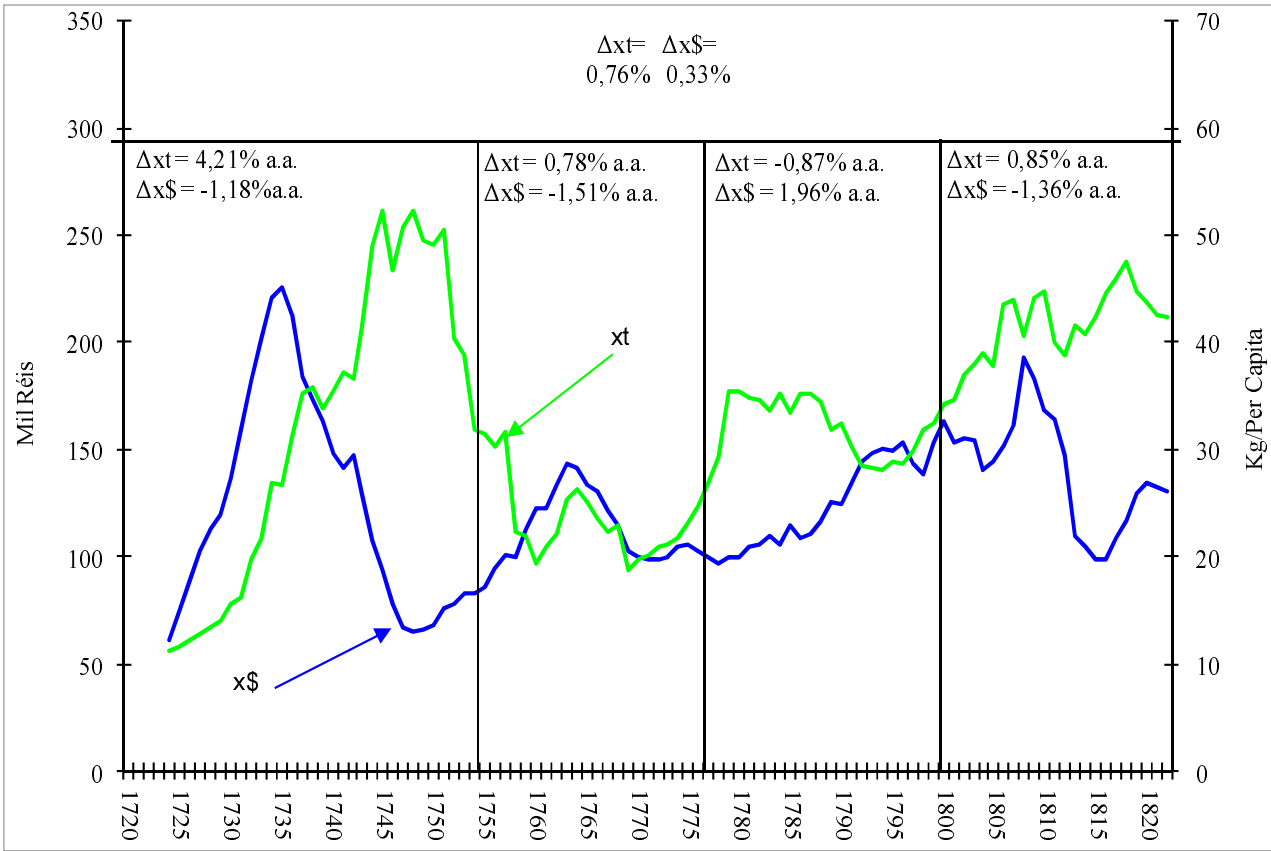

Fonte: Tabela 1 do Anexo.

Por outro lado, comparando as taxas verificadas para o Grão-Pará entre 1720 e $1822 \mathrm{com}$ as obtidas a partir das estimativas de Maddison (2009) para o mundo, Portugal e Brasil, entre 1700 e 1820, revela-se que a taxa de crescimento de Y\$ $(2,3 \%)$ é o quádruplo da expansão do mundo e de Portugal no período. Por seu turno, as taxas de incremento de $\mathrm{Y} \$$ e $X \$$ representaram 2,4 e 2 vezes a do 
crescimento do Brasil no mesmo período. Enquanto o PIB per capita crescia a $0,07 \%$ e $0,10 \%$, e $0,28 \%$ a.a., respectivamente, no mundo, em Portugal e no Brasil, no Grão-Pará as exportações per capita cresciam, a preços do mercado mundial, a 1,6\% e, a preços de Belém, a 1,1\% (Cf. Gráfico 4).

Gráfico 4

Comparação das taxas de crescimento do Valor da Exportação e Valor Bruto da Produção do GrãoPará, total e per capita (1720 a 1820), com as taxas de crescimento do Produto Interno Bruto do Mundo, de Portugal e do Brasil, total e per capita (1700 a 1820)

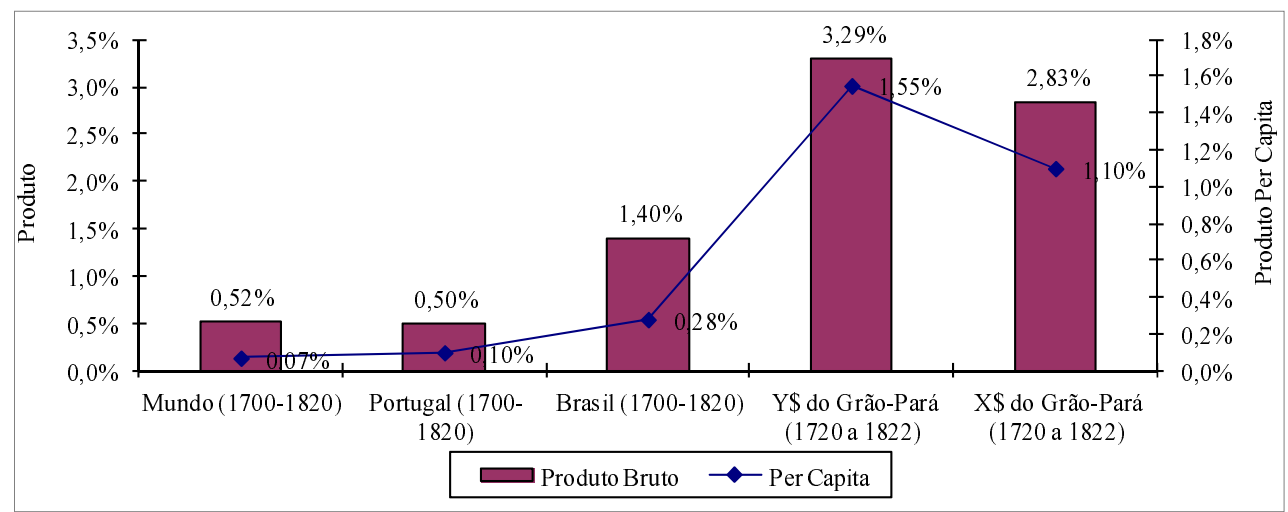

Fonte: Tabela 2 do Anexo e Maddison (2009).

\section{Expansão e distribuição de resultados}

Tal dinâmica é avaliada, de modo distinto, por três diferentes grupos de protagonistas: A) Os agentes econômicos que, na metrópole, gerem o processo de transformação pelo comércio ou pela indústria de XT em Y\$; B) os agentes que garantem os rendimentos do Estado Colonial e C) os agentes que, na Colônia, gerem os fundamentos da produção de XT.

Para os agentes na metrópole (de tipo A), XT chega como um custo $\mathrm{X} \$=$ $\mathrm{XT} . \mathrm{x} \$$, definido por $\mathrm{x} \$$ - preço pago na Colônia aos agentes lá assentados (de tipo C) - e lhes escapa como uma receita $\mathrm{Y} \$=\mathrm{XT} . \mathrm{y} \$$, definida por $\mathrm{y} \$$ - preço pago no mercado mundial pelos produtos da Colônia. Esses agentes observam o mundo pela relação $m$, acima discutida, que representa a formação de valor adicionado (m), na metrópole, que inclui lucro mercantil, processamento industrial e receitas de serviços, como transporte, salários e rendimentos diversos. Expressando, em $y \$$, o grau de monopólio da metrópole no mercado mundial e, em $\mathrm{x} \$$, o grau de monopsônio na colônia, $m(=\mathrm{Y} \$ / \mathrm{X} \$=\mathrm{y} \$ . \mathrm{XT} / \mathrm{x} \$ . \mathrm{XT}=\mathrm{y} \$ \mathrm{x} \$)$ indica, por outra parte, a massa de valor cujo acesso justifica o empreendimento colonial à luz de seus gestores: importa, afinal, o montante $[(y \$-x \$) / y$ ].Y\$ - sua participação no esforço total. 
Gráfico 5

Evolução da participação relativa dos diversos conjuntos de agentes fundamentais na economia colonial 1720 a 1820: \% de Y\$. Médias móveis quinquenais

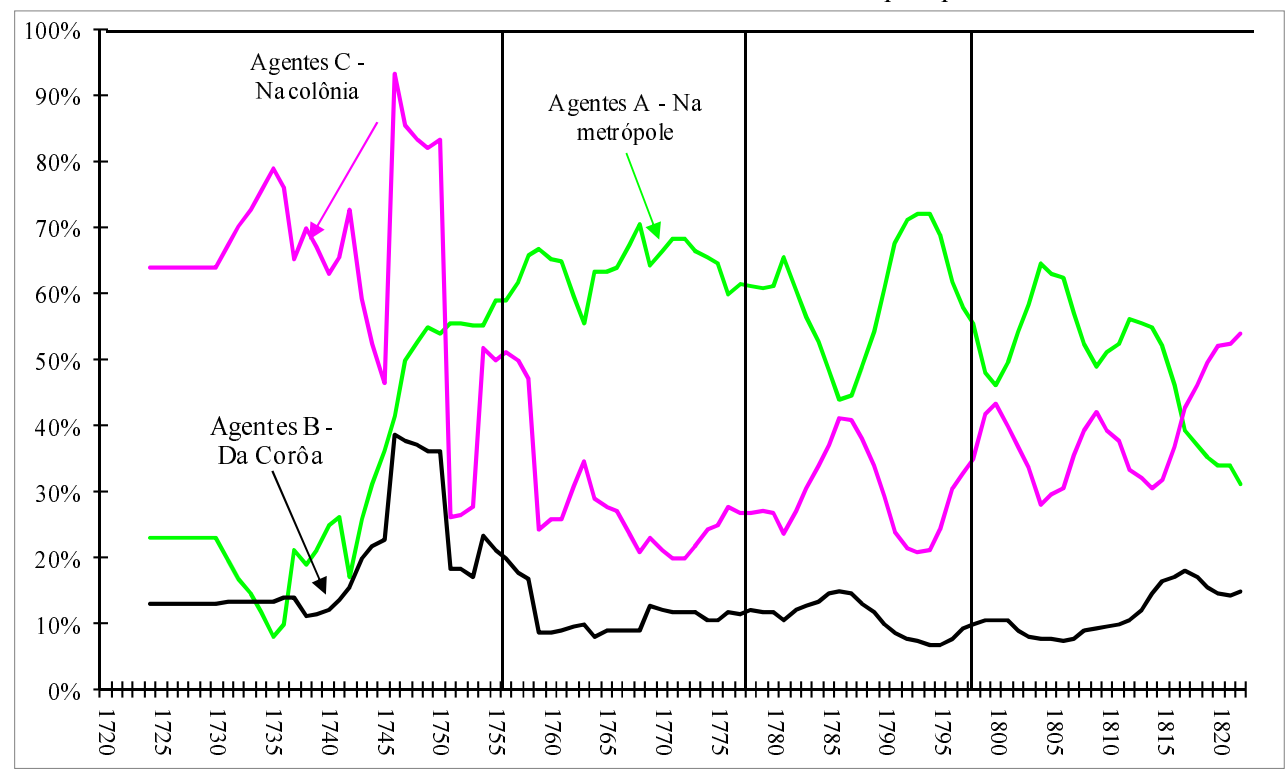

Fonte: Tabela 1 do Anexo.

Os agentes do estado (de tipo B), imputam tributos i sobre XT em montante i.XT, ou seja, parte dos custos de operação dos agentes de tipo $\mathrm{C}^{5}$. Esses últimos observam o mundo pela relação $(x \$-c \$) / c \$$, onde $c \$$ é seu custo de operação na obtenção de XT, do qual faz parte i.XT. Para eles, em conjunto, importa o montante $[(\mathrm{x} \$-\mathrm{c} \$) / \mathrm{y} \$]$.Y $\$$, isto é, a forma objetiva como participam do empreendimento colonial. Dado que tal participação será máxima se $\mathrm{x} \$$ for máximo e c\$ mínimo, estabelece-se o potencial de conflito, de um lado, em torno de $\mathrm{x} \$$ entre os agentes de tipo $\mathrm{C}$ e os de tipo $\mathrm{A}$, e, de outro, em torno de i entre os primeiros e os agentes de tipo B.

Para todo o período, a tensão em torno de $\mathrm{x} \$$, na Colônia Amazônica, refletiu-se na sua taxa de crescimento menor comparativamente à dos preços do resto do mundo, $\mathrm{y} \$$, implicando, como se viu, na ampliação da taxa de valor adicionado $(\mathrm{m})$ dos agentes da metrópole a $0,4 \%$ a.a. (Gráfico 2). Com isso, amplia-se sistematicamente sua participação no empreendimento colonial, a $0,9 \%$ a.a., em detrimento da participação do valor retido como imposto, que o reduz a $0,3 \%$ a.a., e da participação dos agentes agrupados em $\mathrm{C}$, que caiu a $-0,4 \%$ a.a. (ver Gráfico 5 e Tabela A-2).

(5) Alden (1974) apresenta, no Apêndice III, as fórmulas de cálculo de impostos sobre o cacau e sobre outras drogas do sertão, como o cravo. Para o cacau, 410 réis/arroba; para o cravo, 620 réis/arroba. Custos de embalagem do cacau, 100 réis/arroba; para o cravo, 200 réis/cesto.

Economia e Sociedade, Campinas, v. 21, n. 1 (44), p. 197-219, abr. 2012. 


\section{A dinâmica da Colônia e seus fundamentos técnicos: a oposição extrativismo $\mathbf{x}$ agricultura}

Ao longo do período estudado, o valor exportado agrícola cresceu a 5,2\% a.a. e o valor da produção extrativista a 2,3\% a.a. (Cf. Gráfico 6). De modo que, ao longo do período, houve um reposicionamento notável da agricultura, sem, contudo, contestar o domínio da produção extrativista, setor que nos últimos cinco anos do Período Colonial representava $61 \%$ do valor da exportação (Cf. Gráfico 7).

Gráfico 6

Evolução do valor exportado de produtos extrativos e agropecuários da economia colonial amazônica 1720 a 1820:\$000 Réis, Médias móveis quinquenais

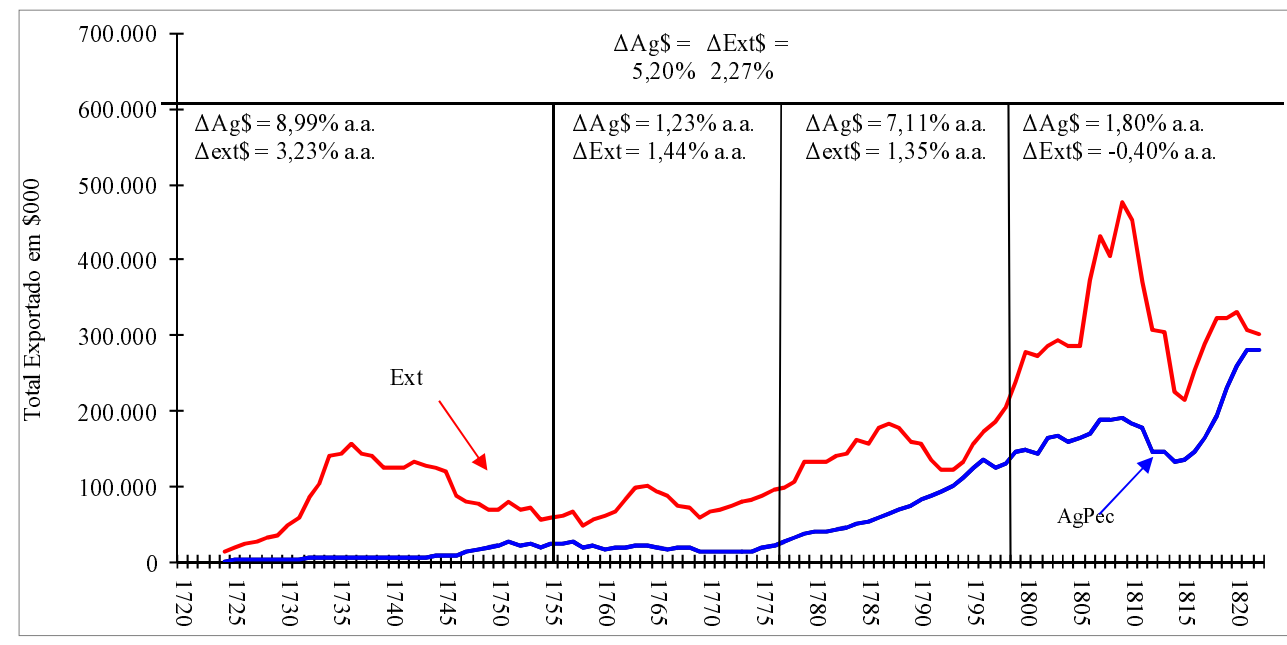

Fonte: Tabelas 1 e 2 do Anexo.

Gráfico 7

Evolução da participação relativa dos grupos de produtos da pauta de exportação da economia colonial amazônica 1720 a 1820: \% de X\$. Médias móveis quinquenais

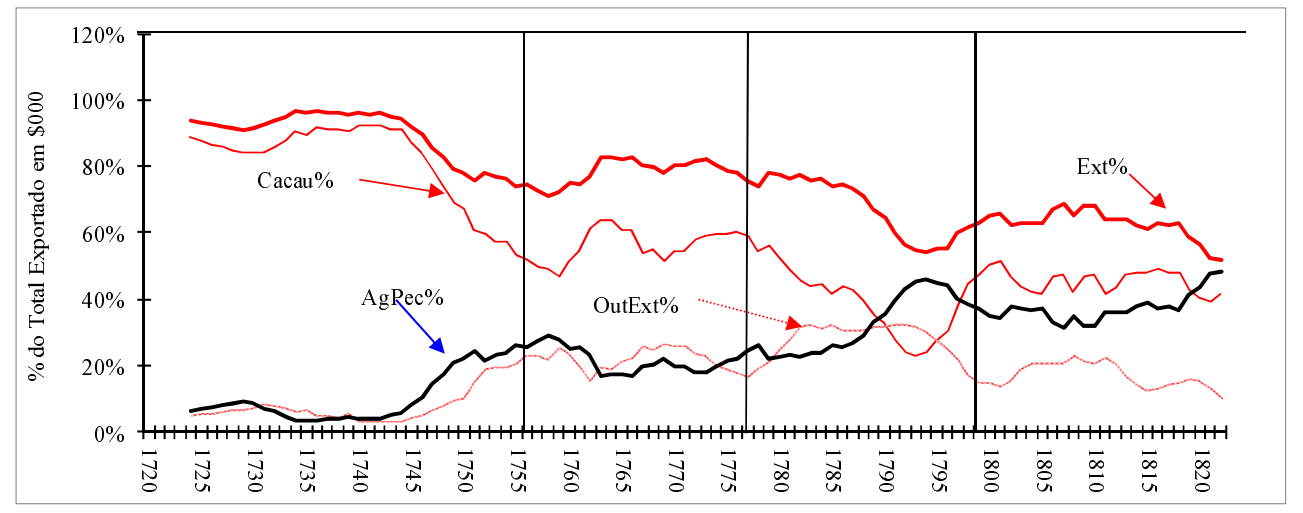

Fonte: Tabelas 1 e 2 do Anexo. 


\section{Dinâmica econômica e distinção de fundamentos em períodos relevantes da história institucional do Grão-Pará}

Nossas séries cobrem quatro períodos da história colonial da região:

\section{0 a 1755}

Trata-se de um período com forte regulamentação dos fundamentos produtivos por conta da prevalência do Regimento das Missões, que estabeleceu as regras de repartição da força de trabalho dos índios aldeados, fraca regulamentação de comércio e forte regulação sistêmica por ativas relações espontâneas com o mercado mundial.

Para os 35 anos desse período dominado pelas Missões, a taxa média anual de crescimento da economia colonial amazônica, expressa em Y\$, foi de $6,3 \%$ a.a., dos quais apenas $1 \%$ a.a., explica-se pelo crescimento da população sob controle do sistema colonial. A forte expansão - a mais rápida observada em todo o período - deve-se, sobretudo, à melhoria das condições internas de produção, dado que x cresce a 3\% a.a. As condições externas, expressas em $\mathrm{m}$, evoluem também positivamente, porém à taxa bem menor, de 2,2\%.

Por seu turno, a evolução favorável de $\mathrm{x}$ deve-se unicamente ao crescimento da produtividade física a 4,2\% a.a., a maior verificada em todo o Período Colonial (Cf. Gráfico 3), dado que os preços internos, em média, declinaram a $-1,2 \%$ a.a. (Cf. Gráfico 2).

Na maior parte do tempo, a apropriação do excedente se fez em proporção superior a 50\% em favor dos agentes de tipo C na Colônia. No final do período, a situação se inverte com a participação dos agentes de tipo A (na metrópole) crescendo mais da metade e os agentes de tipo B, da Coroa, em aproximadamente $1 / 4$.

A demonstração de eficiência produtiva interna e capacidade expansiva no período associa-se a formas de produção extrativistas nas quais domina a coleta do cacau, representando, aproximadamente, o total da produção até 1745. A partir de então, começa a ganhar expressão o valor exportado agrícola, que, nos últimos cinco anos do período, atingiu participações expressivas, acima de $20 \%$ do total da Colônia.

\section{6 a 1777}

Trata-se de período com forte regulamentação dos fundamentos produtivos pela ascensão do Diretório dos Índios, que coloca os aldeamentos sob gestão laica, e forte regulamentação no acesso à circulação, dado o monopólio da Companhia de Comércio do Grão-Pará e do Maranhão. O subperíodo é também 
marcado por uma fraca, porém crescente, regulação sistêmica - com tênues relações de livre comércio.

Nos primeiros 22 anos de vigência do Diretório até o encerramento das atividades da Companhia de Comércio, a economia colonial amazônica teve crescimento modesto de $1,5 \%$ a.a. (Cf. Gráfico 1). A produção cresceu a taxas de 3,1\% a.a., mais como um resultado do crescimento da população, a 2,2\% a.a., que pelo incremento da produtividade, que se fez a meros $0,8 \%$ a.a. (Cf. Gráfico 3).

As relações externas fizeram-se sob a égide de preços declinantes, a -1,6\% a.a., no mercado mundial, tendência que, mediada pela nova institucionalidade da Companhia, se refletiu em queda mais rápida no interior da Colônia, a -1,5\% a.a. (Cf. Gráfico 3).

Tal evolução manteve elevadas e crescentes, não obstante fortemente oscilantes, as taxas de crescimento de $\mathrm{m}$, a capacidade de formação do valor adicionado na metrópole (Gráfico 2) e a participação dos seus agentes nos rendimentos totais (Gráfico 3). Ao lado disso, o baixo crescimento da produtividade e a queda nos preços de exportação produziram uma crise na rentabilidade per capita, que caiu, no período, à taxa de $-0,7 \%$.

Sobre os propósitos de implantar, enfim, uma economia de base agrícola para a demonstração do que se menciona esforços na aquisição de escravos negros e introdução de variedades novas de produtos agrícolas, como arroz, algodão e cana, as evidências não são claras. Em rigor, o valor da produção exportada regional manteve o perfil herdado do período anterior, seja no que se refere à dominância do extrativismo de coleta - a média de participação no início, ao longo e no final do período oscila em torno de $80 \%$, (Cf. Gráfico 7 e Tabela A-1) -, seja no que se refere à própria agricultura - os setores cresceram a taxas baixas e semelhantes, o extrativismo a 1,4\%. a.a., mais rápido que a agricultura, a 1,2\% a.a. Trata-se, porém, de caso a investigar - a queda nos preços internos poderia estar encobrindo uma capacidade produtiva que depois se revelaria.

\section{8 a 1798}

Trata-se de período caracterizado por forte regulamentação do acesso aos fundamentos produtivos, pela prevalência, não obstante em ocaso, dos Diretórios, e crescente regulação sistêmica por um mercado livre em expansão com a formação de um capital mercantil regional.

Sobre estas bases estruturais e mercantis internas, sem a governança da Companhia e seu mandato de monopólio nas relações mercantis externas, a economia colonial como um todo (Y\$) mais que duplica a taxa de crescimento para 3,9\% entre 1778 e 1798, comparativamente ao período anterior. Evolução, em parte, explicada pelo crescimento da população a $2,1 \%$, em parte, pelo 
crescimento interno da produtividade a $0,9 \%$ e por preços em recuperação no mercado externo a $2,5 \%$ a.a. Dado que os preços no mercado interno cresceram em ritmo inferior a 2,0\% a.a., a formação de valor adicionado apresentou-se a $0,6 \%$ a.a., mantendo, não obstante, com maior instabilidade, a participação relativa dos agentes na metrópole.

$\mathrm{O}$ crescimento da produtividade somado à elevação dos preços internos iniciou um processo de recuperação do valor das exportações per capita a $1,1 \%$ a.a.

Nessa fase, a agricultura passa a crescer em ritmo bem superior ao extrativismo, respectivamente, a 7,1\% a.a. e 1,3\% a.a., levando às mais expressivas participações da primeira no valor das exportações da Colônia. A produção extrativista sofre também uma diversificação sem precedentes com o valor exportado de cacau atingindo a mais baixa expressão em todo o período.

\section{9 a 1820}

Trata-se de um período desregulamentado, tanto no que se refere às condições da produção, posto que extintos os Diretórios, quanto às de comércio, já livres, há muito, da tutela da Companhia de Comércio. A taxa de crescimento de $\mathrm{Y} \$$, de $2,1 \%$ a.a., é a menor de todo o período examinado para uma população crescente a 1,1\% a.a. As condições externas, com queda de -2,7\% a.a., explicam mais efetivamente a performance de y que as condições internas, dado que $\mathrm{x}$ cai a meros $-0,6 \%$ a.a. numa média de fortes oscilações, das quais constam os mais elevados níveis de $\mathrm{x}$ jamais atingidos na Colônia.

Em rigor, a segunda metade do período reflete uma crise que não é exclusiva da Colônia do Grão-Pará - ela se mostra também e ainda mais grave para a Colônia do Brasil. Vale a pena esmiuçar esta questão. A exportação per capita do Grão-Pará permite comparação com a da Colônia do Brasil para um período de aproximadamente $1 / 4$ século, que, basicamente, coincide com o último período de nossa análise. Utilizando a relação entre os valores das exportações do Brasil (Simonsen, 1978) e as populações das séries demográficas históricas publicadas pelo IBGE (1990), o Gráfico 2 mostra as exportações per capita do Brasil em uma linha negra, ladeando duas linhas vermelhas das exportações per capita do Grão-Pará - uma linha vermelha cheia, que é continuação da exposição dos valores de todo o período, utilizando a série de população baseada em fontes e metodologias, esclarecidas na Tabela 1 do Anexo, e outra linha vermelha sombreada, obtida na mesma fonte (IBGE, 1990) da série que se utilizou para o Brasil.

O que se constata é interessante: a) utilizando os dados do IBGE, o formato da evolução de x para o Grão-Pará não altera de modo importante, ou 
seja, com esses dados, os valores de x são um pouco maiores nos anos iniciais e um pouco menores nos anos finais, coincidindo, praticamente, nos demais; b) os valores das exportações per capita do Brasil são maiores que os de x da nossa série original nos primeiros anos, literalmente coincidindo com os valores da linha sombreada. A partir de 1805, os valores para o Brasil são significativamente menores que os valores da linha sombreada e, mais ainda, que os da linha cheia original. Demonstra-se, assim, que as condições internas da Colônia do Brasil para o sucesso do empreendimento colonial se mostravam, naquele período, dominantemente inferiores em relação à Colônia do Grão-Pará.

Deve-se sublinhar um outro ponto em relação a essa fase final do Período Colonial: cresce a capacidade de produção agrícola, a quantidade exportada dos produtos agropecuários, avançando, no período, a 3,4\% a.a. Todavia, dado que os preços caem a 1,6\% a.a., o crescimento da receita de exportação desses produtos se faz a um ritmo mais baixo, de $1,8 \%$ a.a. Não obstante tratar-se de ritmo bem superior ao da produção extrativista, cuja capacidade produtiva se expande a $0,6 \%$ a.a., com preços decrescentes a $-1 \%$ a.a., tal evolução não foi suficiente para contestar o domínio do extrativismo de coleta, setor produtivo que, ainda nos últimos cinco anos do Período Colonial, representava $61 \%$ da economia.

\section{Considerações finais}

Nossos resultados indicam, primeiro, que, no Período Colonial na Amazônia, se construiu um sistema econômico expansivo, com capacidade produtiva (escala de produção), rentabilidade e produtividade crescentes, além de estabilidade compatível com necessidades sistêmicas de reprodução de longo prazo.

Segundo, que tal construção se confirmou sistêmica, crescente e eficiente para as necessidades reprodutivas dos segmentos sociais fundamentais na sua constituição e gestão. Tais necessidades, por outra parte, parecem ter sido atendidas diferenciadamente ao longo do tempo, indicando dinâmicas baseadas em conflito e no peso das soluções institucionais.

Terceiro, a dinâmica da economia teve por base principal o extrativismo de coleta e as regras derivadas de diferentes soluções institucionais para o uso da capacidade de trabalho dos índios aldeados, de modo que o extrativismo se estabeleceu como o fundamento principal (de fato e de direito) dessa economia colonial, sendo as demonstrações de eficiência produtiva, como o crescimento continuado na produtividade, indissociáveis dessa combinação.

Quarto, o período pombalino não demonstrou ser o momento em que, enfim, se estabeleceram os fundamentos da economia, tampouco, o evento genial perdido - para o qual não se verificariam consequências relevantes na perspectiva 
da constituição da economia regional. $\mathrm{O}$ que vimos indica ser essa fase, com o "Diretório dos Índios" e a "Companhia", um fundamental e criativo momento de uma trajetória iniciada com o "Regimento das Missões", que, por uma parte, se impôs ao protagonismo reformador que marcou o subperíodo e, por outra, dela recebeu condicionantes que marcaram indelevelmente os próximos períodos.

Quinto, o que resulta nas fases finais do Período Colonial é uma economia impar com capacidade crescente de lidar equilibradamente com dois exigentes departamentos: um, extrativista, associado ao bioma único e altamente complexo, e, outro, agrícola, no contexto edafoclimático também único da região. Os sistemas de produção nesses dois departamentos exigiram processos não triviais de aprendizado, o que propriamente qualificou a especificidade da trajetória: tanto os que permitiram acessar sistematicamente e com produtividade crescente o bioma originário amazônico quanto os que possibilitaram estabelecer uma agricultura adaptada às condições peculiares da região.

Não é por coincidência que estas são, precisamente, as questões maiores quando hodiernamente se discute as alternativas de desenvolvimento (com esperança de sustentabilidade) para a Amazônia.

\section{Referências bibliográficas}

ALDEN, D. O significado da produção de cacau na Região Amazônia. Belém: NAEAUFPa, 1974.

ALMEIDA, R. H. O firetório dos índios: um projeto de civilização no Brasil do século XVIII. Brasília: Editora Universidade de Brasília, 1997.

AZEVEDO, J. L. D. Os Jesuitas no Grão-Pará: suas missões e a colonização. Belém, Secult, 1999.

CARDOSO, C. F. Economia e sociedade em áreas periféricas: Guiana Francesa e Pará (1750-1817). Rio de Janeiro: Edição Graal, 1984.

CARREIRA, A. A Companhia Geral do Grão-Pará e Maranhão: o comércio intercontinental Portugal-África-Brasil na segunda metade do século XVIII. São Paulo: Editora Nacional, 1988.

COSTA, F. de A. Amazonien - Bauern, Märkte und Kapitalakkumulation. SaarbrückenForlauderdale: Verlag Breitenbach Publishers, 1989.

COSTA, O. O povoamento da Amazônia. Revista Brasileira de Estudos Políticos, Belo Horizonte, UFMG, n. 27, jul. 1969.

DANIEL, J. Pe. Tesouro descoberto no máximo Rio Amazonas. Rio de Janeiro: Contraponto, 2004. 2v. 
DIAS, M. N. Fomento e mercantilismo: a Companhia Geral do Grão Pará e Maranhão (1755-1778). Belém: UFPA, 1970. 2 v.

DOMINGUES, A. Quando os índios eram vassalos: colonização e relações de poder no Norte do Brasil na segunda metade do século XVIII. Lisboa: Comissão Nacional Comemorações dos Descobrimentos Portugueses. 2000.

FURTADO, C. Formação econômica do Brasil. São Paulo: Companhia Editora Nacional, 1976.

IBGE. Estatísticas Históricas do Brasil: Séries Econômicas e Sociais 1550 a 1988. Rio de Janeiro: IBGE, 1990.

MADDISON, A. Historical statistics for the world economy: 1-2003 AD. Groningen, 2009, GGDC. Disponível em: http://www.ggdc.net/maddison.

MARANHO, M. F. O moinho e o engenho: São Paulo e Pernambuco em diferentes contextos e atribuições no Império Colonial Português 1580 - 1720. 2006. Tese (Doutorado)-Departamento de História, Faculdade de Filosofia, Letras e Ciências Humanas, Universidade de São Paulo / FFLCH - USP, 2006.

MENDONÇA, M. C. A Amazônia na Época Pombalina. Rio de Janeiro: Imprensa Nacional, 1963. 2v.

NEVES, A. B. Os Soldados de Cristo na Terra dos Papagaios. 1987.

PRADO JR., C. História econômica do Brasil. São Paulo: Editora Brasiliense, 1987.

REIS, A. C. F. O processo histórico da economia amazônica. Rio de Janeiro: Imprensa Nacional, 1944.

SANTOS, R. História econômica da Amazônia (1800-1920). São Paulo: T. A. Queiroz, 1980.

SIMONSEN, R. C. História econômica do Brasil (1500/1820). São Paulo: Companhia Editora Nacional, 1978.

SHIKIDA, C. D. Apontamentos sobre a economia política da Companhia Geral de Comércio do Grão-Pará e Maranhão. Revista de Economia e Administração, São Paulo, IBMEC, v. 6, p. 175-190, 2007.

SODRÉ, N. W. Formação histórica do Brasil. Rio de Janeiro: Bertrand Brasil, 1987.

TOCANTINS, L. Amazônia: natureza, homem e tempo. Rio de Janeiro: Conquista, 1960. 


\section{Anexo}

Tabela 1

Principais variáveis da economia colonial do Grão-Pará

\begin{tabular}{|c|c|c|c|c|c|c|c|c|c|c|c|c|c|c|c|}
\hline \multirow{4}{*}{ Ano } & \multicolumn{11}{|c|}{ Exportações para a metrópole } & \multicolumn{3}{|c|}{ Valor no mercado mundial } & \multirow{4}{*}{$\begin{array}{l}\text { População da } \\
\text { Colônia } \\
\text { (15) }\end{array}$} \\
\hline & \multicolumn{4}{|c|}{ Produção exportada } & \multicolumn{3}{|c|}{ Preços } & \multicolumn{4}{|c|}{ Valor das exportações } & \multicolumn{2}{|c|}{ Cacau } & \multirow{3}{*}{$\begin{array}{c}\text { Total da } \\
\text { Produção } \\
\text { (14) }\end{array}$} & \\
\hline & \multicolumn{2}{|c|}{ Extrativista } & \multirow{2}{*}{$\begin{array}{l}\text { Agrícola } \\
\text { (3) }\end{array}$} & \multirow{2}{*}{$\begin{array}{c}\text { Total } \\
(4)\end{array}$} & \multicolumn{2}{|c|}{ Extrativista } & \multirow{2}{*}{$\begin{array}{c}\text { Agrícola } \\
(7)\end{array}$} & \multicolumn{2}{|c|}{ Extrativista } & \multirow{2}{*}{$\begin{array}{c}\text { Agrícola } \\
(10)\end{array}$} & \multirow{2}{*}{$\begin{array}{c}\text { Total } \\
(11)\end{array}$} & \multirow{2}{*}{$\begin{array}{c}\text { Preços } \\
(12)\end{array}$} & \multirow{2}{*}{$\begin{array}{l}\text { Total na } \\
\text { metrópole } \\
\text { (13) }\end{array}$} & & \\
\hline & $\begin{array}{l}\text { Cacau } \\
\text { (1) }\end{array}$ & \begin{tabular}{|c} 
Outra \\
(2)
\end{tabular} & & & $\begin{array}{c}\text { Cacau } \\
\text { (5) }\end{array}$ & $\begin{array}{l}\text { Outra } \\
(6)\end{array}$ & & $\begin{array}{c}\text { Cacau } \\
(8)\end{array}$ & $\begin{array}{c}\text { Outra } \\
\text { (9) }\end{array}$ & & & & & & \\
\hline 1720 & 87 & 118 & 15 & 220 & 1,5 & 0,06 & 0,51 & 9.032 & 495 & 513 & 1.008 & 1,96 & 11.794 & 13.110 & 21.354 \\
\hline 1721 & 92 & 119 & 17 & 228 & 1,5 & 0,06 & 0,47 & 9.524 & 523 & 545 & 1.068 & 1,96 & 12.437 & 13.831 & 21.569 \\
\hline 1722 & 97 & 119 & 19 & 235 & 1,5 & 0,07 & 0,52 & 10.04 & 589 & 686 & 1.275 & 1,96 & 13.115 & 14.779 & 21.787 \\
\hline 1723 & 103 & 119 & 34 & 256 & 2,4 & 0,13 & 0,56 & 16.94 & 1.057 & 1.323 & 2.379 & 3,13 & 22.127 & 25.234 & 22.007 \\
\hline 1724 & 108 & 120 & 44 & 272 & 2,8 & 0,17 & 0,6 & 20.84 & 1.378 & 1.808 & 3.186 & 3,66 & 27.222 & 31.382 & 22.229 \\
\hline 1725 & 114 & 120 & 61 & 295 & 3,6 & 0,24 & 0,63 & 28.26 & 1.992 & 2.675 & 4.667 & 4,7 & 36.908 & 43.002 & 22.454 \\
\hline 1726 & 120 & 120 & 65 & 306 & 3,6 & 0,28 & 0,67 & 29.80 & 2.325 & 3.028 & 5.353 & 4,7 & 38.920 & 45.910 & 22.681 \\
\hline 1727 & 127 & 121 & 69 & 317 & 3,6 & 0,31 & 0,68 & 31.43 & 2.567 & 3.218 & 5.784 & 4,7 & 41.041 & 48.594 & 22.910 \\
\hline 1728 & 134 & 121 & 75 & 330 & 3,6 & 0,35 & 0,75 & 33.14 & 2.936 & 3.910 & 6.846 & 4,7 & 43.278 & 52.217 & 23.141 \\
\hline 1729 & 141 & 122 & 84 & 347 & 3,6 & 0,37 & 0,72 & 34.95 & 3.107 & 4.171 & 7.278 & 4,7 & 45.637 & 55.140 & 23.375 \\
\hline 1730 & 321 & 133 & 64 & 517 & 4 & 1,04 & 1,04 & 88.25 & 9.550 & 4.556 & 14.106 & 5,22 & 115.246 & 133.664 & 23.611 \\
\hline 1731 & 236 & 128 & 29 & 392 & 4,8 & 1,14 & 1,14 & 78.23 & 10.028 & 2.250 & 12.278 & 5,12 & 82.973 & 95.994 & 23.850 \\
\hline 1732 & 475 & 143 & 127 & 746 & 4,8 & 0,8 & 0,8 & 157.1 & 7.924 & 7.040 & 14.964 & 5,28 & 172.671 & 189.112 & 24.091 \\
\hline 1733 & 380 & 137 & 88 & 606 & 4,8 & 0,65 & 0,65 & 125.6 & 6.162 & 3.964 & 10.127 & 5,38 & 141.024 & 152.386 & 24.334 \\
\hline 1734 & 642 & 154 & 196 & 991 & 4,8 & 0,35 & 0,35 & 212.0 & 3.737 & 4.749 & 8.486 & 5,28 & 233.032 & 242.359 & 24.580 \\
\hline 1735 & 324 & 133 & 65 & 522 & 4,2 & 1,64 & 1,64 & 93.60 & 15.029 & 7.305 & 22.334 & 4,42 & 98.390 & 121.867 & 24.828 \\
\hline 1736 & 638 & 154 & 194 & 985 & 3,6 & 0,23 & 0,23 & 158.0 & 2.412 & 3.047 & 5.458 & 4,31 & 189.153 & 195.687 & 25.079 \\
\hline 1737 & 836 & 166 & 276 & 1.278 & 3,6 & 0,35 & 0,35 & 100.5 & 4.014 & 6.652 & 10.666 & 4,85 & 278.984 & 308.583 & 25.332 \\
\hline 1738 & 454 & 142 & 119 & 715 & 3,6 & 0,46 & 0,46 & 112.6 & 4.524 & 3.783 & 8.307 & 4,74 & 148.240 & 159.173 & 25.588 \\
\hline 1739 & 497 & 145 & 136 & 778 & 3,6 & 0,66 & 0,66 & 123.1 & 6.545 & 6.164 & 12.709 & 4,58 & 156.632 & 172.796 & 25.846 \\
\hline 1740 & 487 & 144 & 132 & 763 & 3 & 0,46 & 0,46 & 100.5 & 4.601 & 4.221 & 8.823 & 3,88 & 130.011 & 141.421 & 26.108 \\
\hline
\end{tabular}


Tabela 1 - Continuação

\begin{tabular}{|c|c|c|c|c|c|c|c|c|c|c|c|c|c|c|c|}
\hline \multirow{4}{*}{ Ano } & \multicolumn{11}{|c|}{ Exportações para a metrópole } & \multicolumn{3}{|c|}{ Valor no mercado mundial } & \multirow{4}{*}{$\begin{array}{c}\text { População da } \\
\text { Colônia } \\
\text { (15) }\end{array}$} \\
\hline & \multicolumn{4}{|c|}{ Produção exportada } & \multicolumn{3}{|c|}{ Preços } & \multicolumn{4}{|c|}{ Valor das exportações } & \multicolumn{2}{|c|}{ Cacau } & \multirow{3}{*}{$\begin{array}{c}\text { Total da } \\
\text { Produção } \\
\text { (14) }\end{array}$} & \\
\hline & \multicolumn{2}{|c|}{ Extrativista } & \multirow{2}{*}{$\begin{array}{c}\text { Agrícola } \\
\text { (3) }\end{array}$} & \multirow{2}{*}{$\begin{array}{l}\text { Total } \\
\text { (4) }\end{array}$} & \multicolumn{2}{|c|}{ Extrativista } & \multirow[b]{2}{*}{$\begin{array}{c}\text { Agrícola } \\
\text { (7) }\end{array}$} & \multicolumn{2}{|c|}{ Extrativista } & \multirow{2}{*}{$\begin{array}{c}\text { Agrícola } \\
\text { (10) }\end{array}$} & \multirow{2}{*}{$\begin{array}{c}\text { Total } \\
\text { (11) }\end{array}$} & \multirow{2}{*}{$\begin{array}{c}\text { Preços } \\
(12)\end{array}$} & \multirow{2}{*}{$\begin{array}{c}\text { Total na } \\
\text { metrópole } \\
(13)\end{array}$} & & \\
\hline & $\begin{array}{l}\text { Cacau } \\
\text { (1) }\end{array}$ & $\begin{array}{l}\text { Outra } \\
\text { (2) }\end{array}$ & & & $\begin{array}{c}\text { Cacau } \\
(5)\end{array}$ & \begin{tabular}{|c|} 
Outra \\
$(6)$
\end{tabular} & & $\begin{array}{c}\text { Cacau } \\
(8)\end{array}$ & $\begin{array}{l}\text { Outra } \\
\text { (9) }\end{array}$ & & & & & & \\
\hline 1741 & 839 & 166 & 276 & 1.281 & 2,8 & 0,27 & 0,27 & 161.6 & 3.140 & 5.217 & 8.357 & 2,69 & 155.412 & 163.447 & 26.371 \\
\hline 1742 & 816 & 165 & 267 & 1.248 & 2,4 & 0,36 & 0,36 & 134.9 & 4.128 & 6.685 & 10.813 & 2,96 & 166.325 & 179.657 & 26.638 \\
\hline 1743 & 920 & 172 & 310 & 1.401 & 1,5 & 0,45 & 0,45 & 94.94 & 5.349 & 9.658 & 15.007 & 2,69 & 170.474 & 197.418 & 26.907 \\
\hline 1744 & 1.218 & 191 & 432 & 1.841 & 1,5 & 0,28 & 0,28 & 111.7 & 3.629 & 8.227 & 11.856 & 2,53 & 212.131 & 234.634 & 27.179 \\
\hline 1745 & 830 & 166 & 273 & 1.269 & 1,2 & 0,87 & 0,87 & 68.55 & 9.948 & 16.369 & 26.317 & 2,37 & 135.356 & 187.317 & 27.453 \\
\hline 1746 & 102 & 119 & 357 & 578 & 1,2 & 0,06 & 0,06 & 8.422 & 516 & 1.543 & 2.059 & 2,32 & 16.282 & 20.262 & 27.730 \\
\hline 1747 & 1.238 & 192 & 441 & 1.871 & 0,8 & 0,95 & 0,95 & 76.76 & 12.545 & 28.794 & 41.340 & 2,37 & 201.923 & 310.656 & 28.010 \\
\hline 1748 & 1.126 & 185 & 395 & 1.706 & 1 & 1 & 1 & 72.89 & 12.738 & 27.204 & 39.942 & 2,26 & 175.357 & 271.445 & 28.293 \\
\hline 1749 & 1.015 & 178 & 349 & 1.541 & 1,2 & 1,06 & 1,06 & 69.01 & 13.008 & 25.537 & 38.545 & 2,29 & 159.851 & 249.123 & 28.579 \\
\hline 1750 & 836 & 166 & 275 & 1.277 & 1 & 1,31 & 1,31 & 69.83 & 15.035 & 24.901 & 39.936 & 2,15 & 123.926 & 194.792 & 28.868 \\
\hline 1751 & 512 & 146 & 142 & 799 & 1 & 2,04 & 2,04 & 35.22 & 20.404 & 19.930 & 40.334 & 2,32 & 81.553 & 174.944 & 29.159 \\
\hline 1752 & 286 & 131 & 49 & 466 & 1 & 1,13 & 1,13 & 19.64 & 10.210 & 3.834 & 14.044 & 2,53 & 49.750 & 85.308 & 29.454 \\
\hline 1753 & 1.025 & 178 & 353 & 1.556 & 1,1 & 1,88 & 1,88 & 77.64 & 23.079 & 45.678 & 68.757 & 2,58 & 182.314 & 343.758 & 29.752 \\
\hline 1754 & 150 & 122 & 316 & 588 & 1,1 & 0,21 & 0,21 & 11.33 & 1.781 & 4.592 & 6.373 & 2,58 & 26.656 & 41.642 & 30.052 \\
\hline 1755 & 843 & 167 & 278 & 1.287 & 1 & 2,46 & 2,46 & 58.00 & 28.190 & 47.040 & 75.230 & 2,69 & 156.169 & 358.730 & 30.356 \\
\hline 1756 & 432 & 123 & 89 & 643 & 1,2 & 3,93 & 3,25 & 35.70 & 33.233 & 19.817 & 53.051 & 2,75 & 81.701 & 203.108 & 30.662 \\
\hline 1757 & 512 & 116 & 83 & 710 & 0,96 & 2,89 & 2,59 & 33.83 & 23.010 & 14.788 & 37.798 & 4,04 & 142.334 & 301.348 & 30.972 \\
\hline 1758 & 116 & 14 & 41 & 170 & 0,96 & 1,52 & 2,23 & 7.642 & 1.470 & 6.244 & 7.714 & 4,23 & 33.650 & 67.620 & 31.285 \\
\hline 1759 & 348 & 127 & 93 & 569 & 1,64 & 2,32 & 2,46 & 39.25 & 20.356 & 15.73 & 36.093 & 4,35 & 104.208 & 200.032 & 31.601 \\
\hline 1760 & 682 & 102 & 145 & 928 & 2 & 2,41 & 2,96 & 93.84 & 16.947 & 29.40 & 46.350 & 4,42 & 207.183 & 309.512 & 31.920 \\
\hline 1761 & 524 & 303 & 123 & 950 & 2 & 1,33 & 3,64 & 72.11 & 27.750 & 30.84 & 58.590 & 4,47 & 161.156 & 292.086 & 32.242 \\
\hline 1762 & 732 & 143 & 74 & 948 & 2,42 & 1,18 & 2,85 & 121.7 & 11.617 & 14.53 & 26.150 & 4,74 & 238.635 & 289.908 & 32.568 \\
\hline 1763 & 487 & 152 & 51 & 689 & 1,75 & 2,71 & 2,65 & 58.56 & 28.237 & 9.308 & 37.545 & 4,04 & 135.319 & 222.071 & 32.897 \\
\hline 1764 & 475 & 180 & 100 & 754 & 1,5 & 1,78 & 3,01 & 49.02 & 21.995 & 20.70 & 42.698 & 3,5 & 114.388 & 214.020 & 33.229 \\
\hline
\end{tabular}


Tabela 1 - Continuação

\begin{tabular}{|c|c|c|c|c|c|c|c|c|c|c|c|c|c|c|c|}
\hline \multirow{4}{*}{ Ano } & \multicolumn{11}{|c|}{ Exportações para a metrópole } & \multicolumn{3}{|c|}{ Valor no mercado mundial } & \multirow{4}{*}{$\begin{array}{c}\text { População da } \\
\text { Colônia } \\
\text { (15) }\end{array}$} \\
\hline & \multicolumn{4}{|c|}{ Produção exportada } & \multicolumn{3}{|c|}{ Preços } & \multicolumn{4}{|c|}{ Valor das exportações } & \multicolumn{2}{|c|}{ Cacau } & \multirow{3}{*}{$\begin{array}{c}\text { Total da } \\
\text { Produção } \\
\text { (14) }\end{array}$} & \\
\hline & \multicolumn{2}{|c|}{ Extrativista } & \multirow{2}{*}{$\begin{array}{c}\text { Agrícola } \\
\text { (3) }\end{array}$} & \multirow{2}{*}{$\begin{array}{l}\text { Total } \\
\text { (4) }\end{array}$} & \multicolumn{2}{|c|}{ Extrativista } & \multirow{2}{*}{$\begin{array}{c}\text { Agrícola } \\
\text { (7) }\end{array}$} & \multicolumn{2}{|c|}{ Extrativista } & \multirow{2}{*}{$\begin{array}{l}\text { Agrícola } \\
\text { (10) }\end{array}$} & \multirow{2}{*}{$\begin{array}{l}\text { Total } \\
(11)\end{array}$} & \multirow{2}{*}{$\begin{array}{l}\text { Preços } \\
(12)\end{array}$} & \multirow{2}{*}{$\begin{array}{c}\text { Total na } \\
\text { metrópole } \\
(13)\end{array}$} & & \\
\hline & $\begin{array}{c}\text { Cacau } \\
(1)\end{array}$ & $\begin{array}{l}\text { Outra } \\
\text { (2) }\end{array}$ & & & $\begin{array}{c}\text { Cacau } \\
(5)\end{array}$ & $\begin{array}{c}\text { Outra } \\
(6)\end{array}$ & & $\begin{array}{c}\text { Cacau } \\
(8)\end{array}$ & $\begin{array}{l}\text { Outra } \\
(9)\end{array}$ & & & & & & \\
\hline 1765 & 459 & 216 & 119 & 794 & 1,5 & 1,56 & 2,46 & 47.41 & 23.161 & 20.09 & 43.253 & 3,39 & 107.236 & 205.056 & 33.565 \\
\hline 1766 & 464 & 163 & 102 & 730 & 1,5 & 2 & 2,62 & 47.91 & 22.517 & 18.40 & 40.919 & 3,61 & 115.247 & 213.668 & 34.566 \\
\hline 1767 & 424 & 266 & 122 & 812 & 1,5 & 1,31 & 2,5 & 43.81 & 23.991 & 20.97 & 44.966 & 4,42 & 128.963 & 261.325 & 35.597 \\
\hline 1768 & 595 & 220 & 60 & 876 & 1,5 & 1,35 & 2,4 & 61.46 & 20.528 & 9.953 & 30.481 & 5,38 & 220.630 & 330.048 & 36.658 \\
\hline 1769 & 14 & 47 & 7 & 68 & 1,5 & 0,42 & 2,73 & 1.446 & 1.346 & 1.379 & 2.725 & 4,85 & 4.687 & 13.521 & 37.752 \\
\hline 1770 & 744 & 312 & 65 & 1.122 & 1,5 & 1,21 & 2,59 & 76.87 & 26.133 & 11.65 & 37.783 & 4,63 & 237.324 & 353.970 & 38.877 \\
\hline 1771 & 560 & 232 & 144 & 936 & 1,5 & 1,73 & 2,26 & 57.81 & 27.665 & 22.44 & 50.106 & 4,52 & 174.334 & 325.425 & 40.037 \\
\hline 1772 & 790 & 146 & 177 & 1.113 & 1,5 & 1,97 & 1,58 & 81.54 & 19.801 & 19.26 & 39.063 & 4,42 & 240.029 & 355.014 & 41.231 \\
\hline 1773 & 854 & 111 & 100 & 1.065 & 1,5 & 2,73 & 1,75 & 88.17 & 20.895 & 12.11 & 33.009 & 3,93 & 231.070 & 317.570 & 42.460 \\
\hline 1774 & 60 & 12 & 117 & 188 & 1,5 & 3,86 & 0,82 & 6.168 & 3.125 & 6.622 & 9.747 & 4,15 & 17.051 & 43.996 & 43.727 \\
\hline 1775 & 1.059 & 97 & 444 & 1.599 & 1,5 & 3,96 & 1,03 & 109.3 & 26.374 & 31.424 & 57.797 & 4,2 & 306.211 & 468.044 & 45.031 \\
\hline 1776 & 849 & 114 & 514 & 1.476 & 1,5 & 3,67 & 1 & 87.68 & 28.698 & 35.534 & 64.232 & 2,7 & 157.834 & 273.455 & 46.374 \\
\hline 1777 & 1.002 & 68 & 731 & 1.802 & 1,5 & 4,37 & 0,9 & 103.5 & 20.366 & 45.141 & 65.507 & 5,7 & 393.342 & 642.273 & 47.756 \\
\hline 1778 & 874 & 169 & 747 & 1.790 & 1,48 & 4,57 & 0,67 & 88.73 & 53.128 & 34.477 & 87.606 & 3,57 & 214.891 & 427.048 & $48.940,40$ \\
\hline 1779 & 841 & 167 & 764 & 1.771 & 1,44 & 4,81 & 0,71 & 83.21 & 55.197 & 37.428 & 92.625 & 3,91 & 226.615 & 478.848 & $50.153,60$ \\
\hline 1780 & 877 & 169 & 781 & 1.827 & 1,45 & 5,04 & 0,76 & 87.58 & 58.562 & 40.982 & 99.544 & 4,26 & 257.140 & 549.393 & $51.397,00$ \\
\hline 1781 & 588 & 150 & 798 & 1.536 & 1,4 & 5,46 & 0,79 & 56.69 & 56.540 & 43.387 & 99.927 & 4,16 & 168.426 & 465.297 & $52.671,10$ \\
\hline 1782 & 1.026 & 178 & 815 & 2.020 & 1,45 & 5,39 & 0,88 & 102.4 & 66.151 & 49.395 & 115.547 & 2,84 & 200.484 & 426.641 & 55.315 \\
\hline 1783 & 766 & 162 & 833 & 1.761 & 1,55 & 5,86 & 0,92 & 81.78 & 65.299 & 52.776 & 118.075 & 2,52 & 132.959 & 324.926 & $56.326,80$ \\
\hline 1784 & 1.464 & 206 & 851 & 2.522 & 1,5 & 5,58 & 1,05 & 151.1 & 79.327 & 61.434 & 140.761 & 2,67 & 269.021 & 519.499 & $57.357,00$ \\
\hline 1785 & 507 & 145 & 870 & 1.522 & 1,65 & 6,55 & 1,02 & 57.55 & 65.438 & 61.102 & 126.540 & 2,97 & 103.450 & 330.896 & $58.406,10$ \\
\hline 1786 & 1.222 & 191 & 889 & 2.302 & 1,65 & 6,22 & 1,18 & 138.8 & 81.811 & 72.108 & 153.919 & 2,97 & 249.528 & 526.186 & $59.474,40$ \\
\hline 1787 & 1.125 & 185 & 909 & 2.218 & 1,4 & 6,14 & 1,22 & 108.4 & 78.152 & 76.241 & 154.393 & 2,97 & 229.637 & 556.702 & $60.562,20$ \\
\hline 1788 & 582 & 150 & 928 & 1.661 & 1,5 & 6,84 & 1,24 & 60.10 & 70.612 & 79.002 & 149.614 & 3,68 & 147.346 & 514.153 & $61.670,00$ \\
\hline
\end{tabular}


Tabela 1 - Continuação

\begin{tabular}{|c|c|c|c|c|c|c|c|c|c|c|c|c|c|c|c|}
\hline \multirow{4}{*}{ Ano } & \multicolumn{11}{|c|}{ Exportações para a metrópole } & \multicolumn{3}{|c|}{ Valor no mercado mundial } & \multirow{4}{*}{$\begin{array}{c}\text { População da } \\
\text { Colônia } \\
(15)\end{array}$} \\
\hline & \multicolumn{4}{|c|}{ Produção exportada } & \multicolumn{3}{|c|}{ Preços } & \multicolumn{4}{|c|}{ Valor das exportações } & \multicolumn{2}{|c|}{ Cacau } & \multirow{3}{*}{$\begin{array}{l}\text { Total da } \\
\text { Produção } \\
\text { (14) }\end{array}$} & \\
\hline & \multicolumn{2}{|c|}{ Extrativista } & \multirow{2}{*}{$\begin{array}{c}\text { Agrícola } \\
\text { (3) }\end{array}$} & \multirow{2}{*}{$\begin{array}{c}\text { Total } \\
(4)\end{array}$} & \multicolumn{2}{|c|}{ Extrativista } & \multirow{2}{*}{$\begin{array}{c}\text { Agrícola } \\
\text { (7) }\end{array}$} & \multicolumn{2}{|c|}{ Extrativista } & \multirow{2}{*}{$\begin{array}{l}\text { Agrícola } \\
\text { (10) }\end{array}$} & \multirow{2}{*}{$\begin{array}{l}\text { Total } \\
\text { (11) }\end{array}$} & \multirow{2}{*}{$\begin{array}{c}\text { Preços } \\
(12)\end{array}$} & \multirow{2}{*}{$\begin{array}{c}\text { Total na } \\
\text { metrópole } \\
(13)\end{array}$} & & \\
\hline & $\begin{array}{c}\text { Cacau } \\
\text { (1) }\end{array}$ & $\begin{array}{c}\text { Outra } \\
\text { (2) }\end{array}$ & & & $\begin{array}{c}\text { Cacau } \\
(5)\end{array}$ & $\begin{array}{c}\text { Outra } \\
(6)\end{array}$ & & $\begin{array}{c}\text { Cacau } \\
(8)\end{array}$ & $\begin{array}{l}\text { Outra } \\
(9)\end{array}$ & & & & & & \\
\hline 1789 & 846 & 167 & 949 & 1.962 & 1 & 6,21 & 1,31 & 58.23 & 71.316 & 85.795 & 157.111 & 3,44 & 200.351 & 740.857 & $62.797,90$ \\
\hline 1790 & 731 & 160 & 970 & 1.860 & 0,85 & 6,29 & 1,38 & 42.75 & 69.044 & 91.807 & 160.851 & 3,68 & 184.998 & 880.923 & $63.946,60$ \\
\hline 1791 & 668 & 156 & 991 & 1.815 & 0,93 & 6,48 & 1,46 & 42.55 & 69.342 & 99.840 & 169.182 & 4,15 & 191.000 & 950.408 & $65.116,20$ \\
\hline 1792 & 617 & 152 & 1.013 & 1.782 & 1,26 & 6,82 & 1,58 & 53.65 & 71.490 & 109.900 & 181.390 & 4,3 & 182.769 & 800.621 & $66.307,20$ \\
\hline 1793 & 567 & 149 & 1.035 & 1.750 & 1,6 & 7,09 & 1,69 & 62.40 & 72.747 & 120.646 & 193.393 & 4,45 & 173.500 & 711.207 & $67.520,00$ \\
\hline 1794 & 879 & 169 & 1.058 & 2.106 & 1,55 & 6,71 & 1,86 & 93.80 & 78.040 & 135.595 & 213.636 & 5,34 & 323.069 & 1.058 .852 & $68.755,00$ \\
\hline 1795 & 1.066 & 181 & 1.081 & 2.328 & 2,1 & 7,1 & 2,11 & 154.0 & 88.513 & 156.629 & 245.143 & 5,34 & 391.724 & 1.014 .895 & $70.012,60$ \\
\hline 1796 & 699 & 158 & 1.104 & 1.961 & 2,5 & 5,62 & 1,96 & 120.3 & 60.946 & 149.217 & 210.163 & 4,33 & 208.361 & 572.364 & 72.597 \\
\hline 1797 & 1.079 & 182 & 1.129 & 2.390 & 2,1 & 3,08 & 0,78 & 156.0 & 38.507 & 60.986 & 99.494 & 4,36 & 323.912 & 530.480 & 74.021 \\
\hline 1798 & 1.371 & 201 & 1.153 & 2.725 & 2,2 & 1,89 & 1,86 & 207.6 & 26.047 & 147.648 & 173.695 & 4,58 & 432.237 & 793.839 & 75.472 \\
\hline 1799 & 1.225 & 191 & 1.179 & 2.595 & 3,2 & 5,73 & 2,71 & 269.7 & 75.365 & 219.948 & 295.313 & 4,8 & 404.695 & 847.665 & 76.952 \\
\hline 1800 & 1.848 & 231 & 1.231 & 3.310 & 2,4 & 8,1 & 1,94 & 305.2 & 128.851 & 164.389 & 293.240 & 5 & 635.969 & 1.246 .885 & 78.461 \\
\hline 1801 & 937 & 173 & 1.231 & 2.340 & 1,9 & 3,06 & 1,42 & 122.5 & 36.421 & 120.122 & 156.542 & 4,6 & 296.614 & 675.612 & 80.000 \\
\hline 1802 & 2.015 & 242 & 1.282 & 3.538 & 1,12 & 5,9 & 1,86 & 154.6 & 98.215 & 164.282 & 262.497 & 4,72 & 654.581 & 1.765 .778 & 80.872 \\
\hline 1803 & 1.790 & 227 & 1.335 & 3.352 & 1,43 & 6,61 & 1,83 & 176.5 & 103.396 & 167.839 & 271.236 & 5,11 & 629.670 & 1.597 .220 & 81.753 \\
\hline 1804 & 1.565 & 213 & 1.390 & 3.168 & 1,75 & 7,77 & 1,84 & 188.5 & 113.848 & 175.944 & 289.791 & 4,84 & 521.577 & 1.323 .057 & 82.643 \\
\hline 1805 & 1.440 & 205 & 1.447 & 3.092 & 3,1 & 9,09 & 1,89 & 307.2 & 128.158 & 187.934 & 316.091 & 5,5 & 545.070 & 1.105 .877 & 83.544 \\
\hline 1806 & 3.081 & 310 & 1.507 & 4.898 & 2,4 & 4,18 & 1,49 & 509.1 & 89.172 & 154.431 & 243.603 & 5,4 & 1.145 .487 & 1.693 .595 & 84.454 \\
\hline 1807 & 2.106 & 248 & 1.569 & 3.923 & 2,3 & 11,84 & 2,37 & 333.4 & 201.818 & 255.745 & 457.563 & 4,6 & 666.951 & 1.582 .077 & 85.374 \\
\hline 1808 & 239 & 128 & 1.634 & 2.001 & 2,45 & 12,31 & 1,52 & 40.34 & 108.581 & 171.013 & 279.593 & 4,72 & 77.743 & 616.508 & 86.304 \\
\hline 1809 & 2.981 & 304 & 1.701 & 4.986 & 2,6 & 6,11 & 1,62 & 533.6 & 127.705 & 189.669 & 317.375 & 4,85 & 994.428 & 1.585 .879 & 87.245 \\
\hline 1810 & 1.529 & 211 & 1.771 & 3.511 & 2,23 & 5,63 & 1,17 & 234.3 & 81.600 & 142.985 & 224.585 & 4,97 & 523.252 & 1.024 .631 & 88.195 \\
\hline 1811 & 963 & 174 & 1.845 & 2.982 & 1,91 & 5,59 & 0,99 & 126.4 & 67.074 & 126.036 & 193.110 & 5,1 & 338.231 & 854.683 & 89.156 \\
\hline 1812 & 1.421 & 204 & 2.000 & 3.625 & 1,63 & 3,51 & 0,75 & 159.9 & 49.193 & 103.848 & 153.040 & 5,24 & 512.504 & 1.002 .814 & 90.128 \\
\hline
\end{tabular}


Tabela 1 - Continuação

\begin{tabular}{|c|c|c|c|c|c|c|c|c|c|c|c|c|c|c|c|}
\hline \multirow{4}{*}{ Ano } & \multicolumn{11}{|c|}{ Exportações para a metrópole } & \multicolumn{3}{|c|}{ Valor no mercado mundial } & \multirow{4}{*}{$\begin{array}{c}\text { População da } \\
\text { Colônia } \\
\text { (15) }\end{array}$} \\
\hline & \multicolumn{4}{|c|}{ Produção exportada } & \multicolumn{3}{|c|}{ Preços } & \multicolumn{4}{|c|}{ Valor das exportações } & \multicolumn{2}{|c|}{ Cacau } & \multirow{3}{*}{$\begin{array}{l}\text { Total da } \\
\text { Produção } \\
\text { (14) }\end{array}$} & \\
\hline & \multicolumn{2}{|c|}{ Extrativista } & \multirow{2}{*}{$\begin{array}{l}\text { Agrícola } \\
\text { (3) }\end{array}$} & \multirow{2}{*}{$\begin{array}{c}\text { Total } \\
(4)\end{array}$} & \multicolumn{2}{|c|}{ Extrativista } & \multirow{2}{*}{$\begin{array}{c}\text { Agrícola } \\
\text { (7) }\end{array}$} & \multicolumn{2}{|c|}{ Extrativista } & \multirow{2}{*}{$\begin{array}{l}\text { Agrícola } \\
\text { (10) }\end{array}$} & \multirow{2}{*}{$\begin{array}{l}\text { Total } \\
\text { (11) }\end{array}$} & \multirow{2}{*}{$\begin{array}{c}\text { Preços } \\
\text { (12) }\end{array}$} & \multirow{2}{*}{$\begin{array}{c}\text { Total na } \\
\text { metrópole } \\
(13)\end{array}$} & & \\
\hline & $\begin{array}{c}\text { Cacau } \\
\text { (1) }\end{array}$ & $\begin{array}{l}\text { Outra } \\
(2)\end{array}$ & & & $\begin{array}{c}\text { Cacau } \\
(5)\end{array}$ & $\begin{array}{l}\text { Outra } \\
(6)\end{array}$ & & $\begin{array}{c}\text { Cacau } \\
(8)\end{array}$ & $\begin{array}{l}\text { Outra } \\
\text { (9) }\end{array}$ & & & & & & \\
\hline 1813 & 1.243 & 192 & 2.000 & 3.435 & 1,2 & 3,15 & 1,17 & 102.6 & 41.683 & 160.5 & 202.275 & 2,2 & 188.194 & 559.031 & 91.109 \\
\hline 1814 & 2.581 & 278 & 2.030 & 4.889 & 1,36 & 0,88 & 0,87 & 242.2 & 16.752 & 122.239 & 138.992 & 2,39 & 424.116 & 667.470 & 92.102 \\
\hline 1815 & 2.111 & 248 & 2.061 & 4.419 & 1,55 & 2,44 & 1,14 & 225.0 & 41.712 & 162.282 & 203.994 & 2,59 & 376.353 & 717.446 & 93.106 \\
\hline 1816 & 1.857 & 232 & 2.124 & 4.213 & 2 & 8,15 & 1,19 & 255.6 & 129.985 & 173.6 & 303.592 & 3,05 & 389.914 & 852.893 & 94.120 \\
\hline 1817 & 1.830 & 230 & 2.395 & 4.455 & 2,05 & 8,35 & 1,24 & 257.8 & 132.207 & 203.928 & 336.135 & 3,11 & 391.893 & 902.718 & 95.061 \\
\hline 1818 & 1.476 & 207 & 2.666 & 4.350 & 2,1 & 7,06 & 1,64 & 212.9 & 100.704 & 301.5 & 402.302 & 3,17 & 322.527 & 931.781 & 96.012 \\
\hline 1819 & 1.419 & 204 & 2.213 & 3.835 & 2,14 & 3,32 & 2,05 & 209.4 & 46.565 & 312.099 & 358.664 & 3,24 & 316.113 & 857.394 & 96.972 \\
\hline 1820 & 1.699 & 222 & 2.248 & 4.169 & 2,2 & 3,39 & 1,95 & 256.7 & 51.682 & 302.531 & 354.213 & 3,3 & 386.113 & 918.818 & 97.942 \\
\hline 1821 & 1.361 & 200 & 2.284 & 3.845 & 2,3 & 3,95 & 1,79 & 215.4 & 54.311 & 281.594 & 335.905 & 3,44 & 321.816 & 823.483 & 98.921 \\
\hline 1822 & 1.979 & 239 & 2.322 & 4.540 & 2,28 & 2,69 & 1,29 & 310.6 & 44.273 & 205.610 & 249.882 & 2,9 & 394.401 & 711.686 & 99.910 \\
\hline
\end{tabular}

Fontes e notas metodológicas:

(1) Produção exportada de Cacau em toneladas. De 1730 a 1822 (Alden, 1974, Apêndice I, p. 60-62). Valores transformados de libras para toneladas. Para 1763 e 1767, os valores em Alden foram corrigidos com base em Dias (1970, p. 316-360). De 1920 a 1929, baseado nas licenças concedidas para a coleta de cacau conhecidas para 1723 (80), 1729 (110), 1730 (250) e 1736 (320) (Cf. Alden, 1974, p. 30-31). Conhecida a produção total do ano de 1730 e 1736, obteve-se as médias de produção por licença, respectivamente, de 1,282 e 1,993 t. Interpolou-se o número de licenças entre 1723 e 1720 pela taxa geométrica de crescimento das concessões entre 1723 e 1729 , multiplicando o resultado para cada ano pela tonelagem média de 1730 .

(2) Produção exportada de outros produtos extrativos ("drogas do sertão"), de 1756 a 1777 (Cf. Dias, 1970, p. 316-360). De 1720 a 1756 e de 1778 a 1820 , aplicou-se os parâmetros da regressão linear entre "outros produtos extrativos" como variável dependente e a produção do cacau, observada nas estatísticas de 1756 a 1777 (a constante de 112,773 expressa uma autonomia elevada e o coeficiente angular de 0,064 , uma dependência positiva, porém baixa em relação ao cacau; o R2 foi de 0,213 ).

(3) Produção agrícola exportada. De 1756 a 1777(Cf.. Dias, 1970, p. 316-360) e anos 1800, 1801, 1812, 1813, 1816 e 1818, (Cf. Barata, 1973, p. 300-330). Fizeram-se interpolações com base nas taxas geométricas verificadas entre os anos conhecidos de cada intervalo. De 1730 a 1755 utilizou-se os parâmetros da regressão linear múltipla obtida com os dados de 1756 a 1777 da produção agrícola, como variável dependente, da produção de cacau (coeficiente 0,461 ) e da produção de outros extrativos (coeficiente -781), com termo constante 19,9 e R2 $=0,555$

(4) Produção exportada total em toneladas: a soma de (1), (2) e (3)

(5) Preços no porto de Belém de cacau em toneladas (em \$000 Réis). De 1730 a 1822 , ver Alden (1974, Apêndice I, p. 60-62). Valores de transformação de arrobas para toneladas. Para 1759, há erro em Alden, corrigido por Dias (Cf. Dias, 1970). De 1720 a 1729, indicações em Alden (1974, p. 30). 
(6) Preços implícitos de outros produtos do extrativismo: (9) $\div(2)$

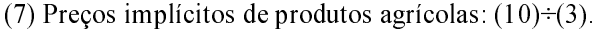

(8) Valor da exportação de cacau: (1) x (5). Resultados cotejados por Alden (1974) e Dias (1970)

(9) Valor das exportações de outros produtos do extrativismo: (11)-(8)-(10).

(10) Valor da produção agrícola exportada. De 1756 a 1777, conferir (Dias, 1970, p. 316-360). Nos anos 1800, 1801, 1812, 1813, 1816 e 1818, conferir Barata (Barata, 1973, p. 300-330). Fizeram-se interpolações com base em incrementos $I=i *(v / a)$, onde I é a taxa de incremento para o ano em questão, " $i$ " a taxa geométrica entre os dois pontos conhecidos de (10), "V" o valor de "V" no ano dividido pela média de "V" no intervalo e "a" a progressão linear da participação de (9) em "V" nos anos conhecidos do intervalo. Isto significa que a agricultura incorpora o total da flutuação da variável agricultura e outros extrativos.

(11) Valor das exportações totais. (Alden, 1974; Barata, 1970). O período 1777 a 1796 por interpolação com base em incrementos I = $i^{*}\left(v^{*} a\right)$, onde I é a taxa de incremento para o ano em questão, "i" a taxa geométrica entre os dois pontos conhecidos de (11), "v" o valor de (8) no ano dividido pela média de (8) no intervalo e "a" a progressão linear da participação de (8) em (11) nos anos conhecidos do intervalo. Isto é, o valor estimado das exportações totais incorpora a flutuação explicável pela variação do cacau.

(12) Preços de revenda a partir de Portugal, cotejados pelas cotações em Amsterdam. Conferir Alden (1974, tab. VII e p. 44-55).

(13) Valor do cacau vendido na metrópole e no resto do mundo. Os valores em (1) x (12)

(14) Valor da produção da Colônia vendida na metrópole e no resto do mundo: [(13)/(8)] * (11).

(15) População da Amazônia com valores apresentados em Cardoso (1984, p. 139), com interpolações com base na taxa geométrica entre os pontos 1816 e 1801: 2,98\% a.a; entre 1802 e 1782: 1,089\% a.a; entre 1782 e 1765 : 1,96\% a.a. De 1765 até 1730 regride à base de $1 \%$ a.a 
Tabela 2

Taxas de evolução das principais variáveis da economia colonial do Grão-Pará

\begin{tabular}{|c|c|c|c|c|c|}
\hline \multirow{2}{*}{ Variáveis } & \multirow{2}{*}{1720 a 1820} & \multicolumn{4}{|c|}{ Subperíodos } \\
\hline & & 1720 a 1750 & 1751 a 1777 & 1778 a1798 & 1799 a 1820 \\
\hline Valor Bruto da Produção no Mercado Mundial (Y\$) & $3,29 \%$ & $6,33 \%$ & $1,54 \%$ & $3,77 \%$ & $-2,19 \%$ \\
\hline Preços no Mercado Mundial (y\$) & $0,79 \%$ & $1,02 \%$ & $-1,41 \%$ & $2,54 \%$ & $-3,97 \%$ \\
\hline Produtividade Física per Capita (xt) & $0,76 \%$ & $4,21 \%$ & $0,78 \%$ & $-0,87 \%$ & $0,75 \%$ \\
\hline População sob Controle do Sistema (P) & $1,71 \%$ & $1,01 \%$ & $2,19 \%$ & $2,08 \%$ & $1,10 \%$ \\
\hline Preços na Colônia (x\$) & $0,33 \%$ & $-1,18 \%$ & $-1,51 \%$ & $1,96 \%$ & $-1,36 \%$ \\
\hline Valor Bruto da Produção na Colônia (X\$) & $2,83 \%$ & $4,02 \%$ & $1,44 \%$ & $3,18 \%$ & $0,47 \%$ \\
\hline Total da Produção em Toneladas (XT) & $2,48 \%$ & $5,26 \%$ & $2,99 \%$ & $1,20 \%$ & $1,86 \%$ \\
\hline Multiplicador (m) & $0,45 \%$ & $2,22 \%$ & $0,10 \%$ & $0,57 \%$ & $-2,65 \%$ \\
\hline Y\$ per capita $(\mathrm{y})$ & $1,55 \%$ & $5,26 \%$ & $-0,64 \%$ & $1,65 \%$ & $-3,25 \%$ \\
\hline X\$ per capita $(\mathrm{x})$ & $1,10 \%$ & $2,98 \%$ & $-0,74 \%$ & $1,07 \%$ & $-0,62 \%$ \\
\hline Valor Adicionado na Metrópole (Agentes Tipo A) & $4,19 \%$ & $10,57 \%$ & $1,66 \%$ & $4,12 \%$ & $-5,09 \%$ \\
\hline Valor Retido como Impostos e Custos (Agentes Tipo B) & $2,88 \%$ & $8,45 \%$ & $2,85 \%$ & $1,19 \%$ & $1,82 \%$ \\
\hline Valor Retido Agentes da Colônia (Agentes Tipo C) & $2,73 \%$ & $4,00 \%$ & $0,82 \%$ & $3,86 \%$ & $0,11 \%$ \\
\hline Valor da Produção Agrícola (Ag\$) & $5,20 \%$ & $8,99 \%$ & $1,23 \%$ & $7,11 \%$ & $1,80 \%$ \\
\hline Valor da Produção Extrativista (Ext\$) & $2,27 \%$ & $3,23 \%$ & $1,44 \%$ & $1,35 \%$ & $-0,40 \%$ \\
\hline Quantidade da Produção Agrícola (AgT) & $4,12 \%$ & $7,80 \%$ & $6,71 \%$ & $2,19 \%$ & $3,41 \%$ \\
\hline Quantidade da Produção Extrativista (ExtT) & $1,74 \%$ & $4,55 \%$ & $1,49 \%$ & $0,32 \%$ & $0,58 \%$ \\
\hline Preços Agrícolas (AgP\$) & $1,05 \%$ & $1,10 \%$ & $-5,14 \%$ & $4,81 \%$ & $-1,56 \%$ \\
\hline Preço dos Extrativos (ExP\$) & $0,52 \%$ & $-1,26 \%$ & $-0,05 \%$ & $1,03 \%$ & $-0,98 \%$ \\
\hline
\end{tabular}

Fonte: Tabela 1. Nota Metodológica: As taxas foram encontradas por regressão linear da transformação logarítmica de cada variável tomada individualmente em relação ao tempo. 